\title{
The effect of maternal health conditions on maternal morbidity in women with a prior cesarean: the role of elective repeat cesarean delivery
}

\author{
Moshe Fridman ${ }^{1}$, Lisa M Korst ${ }^{2}$, Elizabeth Lawton ${ }^{3}$, Naomi Greene ${ }^{4}$, Samia Saeb ${ }^{4}$, Lisa A Nicholas ${ }^{5}$, Kimberly D \\ Gregory*4 \\ ${ }^{1}$ AMF Consulting \\ ${ }^{2}$ Childbirth Research Associates \\ ${ }^{3}$ Maternal, Child and Adolescent Health Division, California Department of Public Health \\ ${ }^{4}$ Department of Obstetrics and Gynecology, Cedars-Sinai Medical Center, Burns Allen Research Institute, United States \\ ${ }^{5}$ Department of Obstetrics and Gynecology, David Geffen School of Medicine at UCLA, Los Angeles, CA, United States
}

Received: January 25, 2019

Accepted: September 9, $2019 \quad$ Online Published: October 29, 2019

DOI: $10.5430 /$ jer.v5n2p17

URL: https://doi.org/10.5430/jer.v5n2p17

\begin{abstract}
Background: We evaluated women with a prior cesarean delivery $(\mathrm{CD})$ who were eligible for elective repeat $\mathrm{CD}$ or trial of labor to test whether the risk of severe maternal morbidity (SMM) was: 1) directly associated with important pre-existing and gestational conditions or 2) indirectly associated (significantly increased or decreased) with the decision to undergo elective repeat $\mathrm{CD}$.

Methods: Women with a prior CD who had inborn, liveborn, term, singleton, vertex deliveries were identified in California 2010-2011 hospital discharge datasets. Using discharge codes, this population was stratified into two groups: attempted labor and elective repeat CD. A mediation model (stratified by younger vs. older women [ $>35$ years]) was built for each of the following maternal conditions (exposure): chronic/gestational diabetes mellitus (DM), chronic/gestational hypertension, heart disease, obesity, and mental health diagnoses. Elective repeat CD was the mediator and SMM was the outcome.

Results: Of 141,535 eligible deliveries, $72.7 \%$ had an elective repeat CD; $2.3 \%$ had SMM, which occurred in $2.2 \%$ of younger vs. $2.6 \%$ of older women. For younger and older women respectively, the modeled total effect odds ratios $(95 \% \mathrm{CI})$ for heart disease were: $10.7(8.5,13.5)$ and $8.8(6.4,12.2)$; for hypertension: $1.7(1.4,1.9)$ and $2.0(1.6,2.4)$; and for mental health diagnoses: 1.9 $(1.6,2.3)$ and $1.7(1.3,2.3)$. Neither DM nor obesity demonstrated a direct effect. Odds ratios for indirect effects were negligible for all models.

Conclusion: Among women with a prior CD, in the presence of important health conditions, the increased risk of SMM mediated by an elective repeat $\mathrm{CD}$ was negligible.
\end{abstract}

Key Words: Prior cesarean delivery, Vaginal birth after cesarean, Severe maternal morbidity, Mediation analysis

\section{INTRODUCTION}

Childbirth-related morbidity is a serious public health concern. Maternal mortality continues to rise, increasing from
7.2 to 17.2 deaths per 100,000 live births from 1987 to $2015 .{ }^{[1]}$ Concurrently, the severe maternal morbidity (SMM) rate has been estimated at $1.5 \%$ for $2015,{ }^{[2]}$ having increased

\footnotetext{
*Correspondence: Kimberly D Gregory; Email: Samia.Saeb@cshs.org; Address: Department of Obstetrics and Gynecology, Cedars-Sinai Medical Center, Burns Allen Research Institute, United States.
} 
$45 \%$ from 2006. ${ }^{[3]}$ SMM includes severe complications of childbirth, e.g., shock, heart failure, renal failure, and pulmonary edema. ${ }^{[3]}$ Postpartum hemorrhage appears to be responsible for approximately half of SMM, followed by complications from hypertension, cardiac disease, infection, and other maternal medical conditions. ${ }^{[4]}$ It is believed that a rising number of women with chronic diseases (e.g., chronic hypertension, diabetes mellitus, and heart disease) are becoming pregnant and that gestational diseases (e.g., gestational diabetes mellitus and preeclampsia) are becoming more prevalent. These trends are putting more pregnant women at risk for SMM ${ }^{[4-10]}$ Heart disease and hypertension are well-known risk factors for both maternal mortality and SMM. ${ }^{[11,12]}$ Several other maternal conditions have been reported to be potential risk factors, and these include: chronic and gestational diabetes mellitus, ${ }^{[4]}$ obesity, which is becoming increasingly prevalent ${ }^{[9,13]}$ and which often accompanies chronic conditions, ${ }^{[7,14,15]}$ and mental health disorders, ${ }^{[7,10,16]}$ which are being more commonly documented at the time of delivery. ${ }^{[9]}$ The potential to avoid SMM may be limited ${ }^{[17]}$ but many believe that opportunities exist for both primary and secondary prevention, particularly if the conditions that put women at risk are detected early in the antenatal course, and access to risk-appropriate care is obtained. ${ }^{[10,18,19]}$ Clinicians have stressed the importance of multidisciplinary teams and timely intervention, particularly for cases of heart disease and hypertension. ${ }^{[20-23]}$ Some have emphasized the importance of trying to minimize SMM by limiting the use of $\mathrm{CD},{ }^{[24,25]}$ which has also been considered a risk factor for SMM. ${ }^{[26]}$ The risk for intra-operative and postpartum complications is higher for women undergoing $\mathrm{CD}$ compared to women undergoing spontaneous vaginal birth. This situation creates a dilemma for patients and physicians deciding on the safest delivery route in the context of these medical conditions. Both elective $\mathrm{CD}$ and attempted labor (and in particular - failed labor) have distinct risks. ${ }^{[27]}$ Compared to a vaginal delivery, the risk ratio for SMM for a failed trial of labor (i.e., CD during labor) is estimated to be 5-6 times that of a vaginal delivery, and the risk ratio for an elective CD estimated to be 2-3 times that of a vaginal delivery. ${ }^{[28-30]}$ Clearly, a successful vaginal delivery would be preferable, but failed labor is very difficult to predict. ${ }^{[31,32]}$ This is especially so for women who have had a prior CD, as a prior $\mathrm{CD}$ in itself is considered an additional risk factor for $\mathrm{SMM},{ }^{[33]}$ with labor predisposing to increased risk of uterine rupture, and repeat $\mathrm{CD}$ predisposing to increased risk of death. ${ }^{[34]}$ Furthermore, failed trial of labor in this population depends heavily on patient and fetal characteristics, and on hospital resources. ${ }^{[35]}$ To accurately quantify the risk of SMM from these pre-existing and gestational conditions, it is important to determine whether elective $\mathrm{CD}$ increases or decreases this risk. In the statistical analysis, treatment of $\mathrm{CD}$ as an independent risk factor generates collinearity, and consequently, the effect of pre-existing and gestational conditions will be underestimated. ${ }^{[36]}$ Instead, analyses should recognize that these conditions have both direct and indirect effects, with the indirect effect of the conditions being mediated through an elective CD. In a previous study ${ }^{[37]}$ we examined the mediating effect of primary $\mathrm{CD}$ in nulliparous, term, singleton, vertex (NTSV) laboring deliveries on the association between SMM and pre-existing and gestational conditions. We used mediation analysis to decompose the risk associated with a condition or exposure into the direct effect (DE) of the condition and the indirect effect (IE) of the condition, where the total effect (TE) equals DE*IE. The "mediator" was emergent CD. Here, we examined similar pre-existing and gestational conditions that have been linked to SMM in a population of women with prior $\mathrm{CD}$, using elective repeat $C D$ as the mediator (see Figure 1). By using only information available at the time the decision regarding elective repeat $\mathrm{CD}$ is made, we sought to evaluate the potential for increased risk of SMM in the presence of maternal pre-existing and gestational conditions due to utilization of elective repeat $\mathrm{CD}$.

\section{METHODS}

\subsection{Data}

The Cedars-Sinai Medical Center Institutional Review Board and the California Health and Human Services Agency Committee for the Protection of Human Subjects approved this study (protocols 00029744 and 12-08-0596, respectively). California 2010-2011 birth cohort files provided the data, which included linked maternal and neonatal hospital discharge datasets, and a link to vital statistics data. These datasets include over $97 \%$ of California births. ${ }^{[38]}$ The study population included singleton, vertex, term (> 37 weeks), inborn, liveborn deliveries of multiparous women with prior CD. Using International Classification of Diseases, Version 9, Clinical Modification (ICD-9-CM) codes, this population was stratified into two groups: attempted labor (based on specific ICD-9-CM codes indicating labor) and elective repeat $\mathrm{CD}$ (based on CD codes and absence of labor codes). Elective repeat $\mathrm{CD}$ was used as the mediator of the risk associated with maternal pre-existing conditions. A previously validated algorithm composed of ICD-9-CM codes, ${ }^{[39]}$ was used to define labor, with minimal modifications (see Table 1). A second analysis, where the definition of the presence of labor was modified to exclude two ICD-9-CM codes (649.81 and 649.82) that indicate that a patient labored prior to a scheduled repeat $\mathrm{CD}$, was performed to test whether this 
affected the study conclusions. Vital statistics data provided information regarding gestational age (obstetrical estimate), maternal body mass index (BMI), and parity. We excluded preterm deliveries of 24-36 completed gestational weeks, and when the obstetrical estimate for gestational age was missing, calculated it from the last menstrual period. All other clini- cal conditions were identified from hospital discharge data, including prior $\mathrm{CD}$ and $\mathrm{CD}$ in the current delivery of interest. Excluded conditions were identified using ICD-9-CM codes as follows: placenta previa $641.0 \times, 641.1 \times$; malpresentation $652 . \times \times$ (except $652.1 \times$ or $652.5 \times)$; and multiple gestation V272, V273, V274, V275, V276, V277, or 651. $\times \times$.

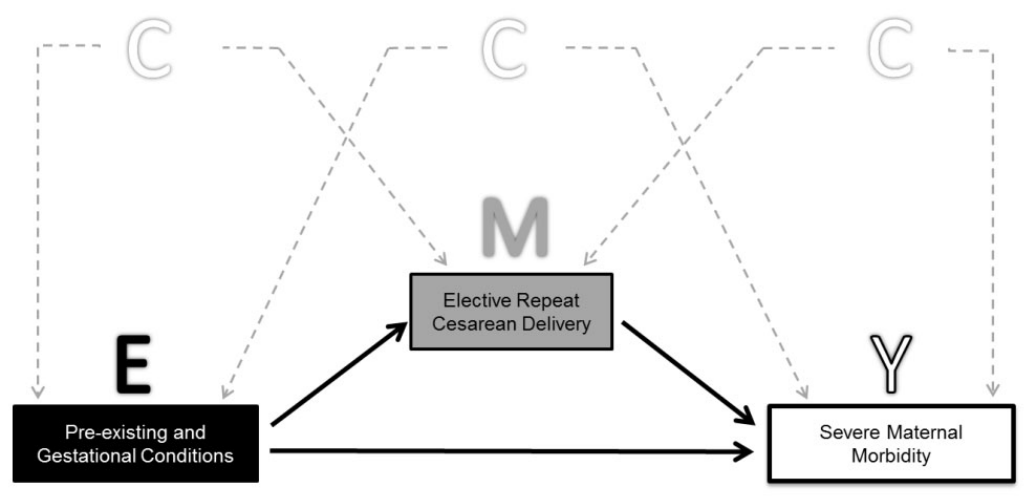

\begin{abstract}
-The same set of potential confounders were used in the equations for both the direct and indirect effects; it includes: control variables: maternal age, race/ethnicity, education, insurance status, prenatal care status, year of delivery; obstetrical conditions: antepartum bleeding/abruption, isoimmune disease, soft tissue conditions (i.e., disorders of the organs and soft tissue of the pelvis); fetal conditions: polyhydramnios, oligohydramnios, intrauterine growth restriction, excessive fetal growth; and other pre-existing conditions were: Herpes virus infection, and presence of hepatic or renal disease.
\end{abstract}

Figure 1. Conceptual model for the risk of severe maternal complication from childbirth. Pre-existing and Gestational Conditions $=$ E (Exposure), Elective Repeat Cesarean Delivery $=$ M (Mediator), Severe Maternal Morbidity $=$ Y $($ Outcome $)$, Confounders $=\mathrm{C}(\text { Vector of Covariates })^{*}$

\subsection{Exposures, mediator, and outcome}

This analysis focused on the effects of important pre-existing and gestational conditions on SMM using information known at the time a decision is made regarding the plan for elective repeat $\mathrm{CD}$ or trial of labor after cesarean (TOLAC). It investigates the role these options play in a realistic scenario, without making 'future' information, such as failed or successful VBAC or other intrapartum or delivery outcomes, available to the model. SMM has been defined by various investigators using hospital discharge data, and the definition used here, ${ }^{[38]}$ is largely consistent with that of the Centers for Disease Control and Prevention (CDC); $;^{[3,40]}$ it includes maternal death (see Supplemental Table 1).

We studied the following pre-existing and gestational conditions: chronic and gestational diabetes mellitus, chronic and gestational hypertension, heart disease, obesity, and mental health disorders. These conditions were identified based on the presence of ICD-9-CM diagnosis or procedure codes in the maternal discharge record for the delivery and are presented in Table 2. Both gestational and chronic hypertension were included in the definition of hypertension. Unspecified hypertension was part of the definition of general hypertension, but not in the specific sub-classification. Analyses of Published by Sciedu Press obesity (BMI > $30 \mathrm{~kg} / \mathrm{m}^{2}$ ), and extreme obesity (BMI > 40 $\mathrm{kg} / \mathrm{m} 2$ ) were conducted. CD was identified by ICD-9-CM codes $669.70,669.71$ or procedure codes $74.0 \times, 74.1 \times$, $74.2 \times, 74.4 \times$, or 74.99. Prior CD was defined by ICD-9CM code 654.2.

\subsection{Confounders}

Socio-demographic characteristics (i.e., Medicaid insurance, mother's highest education level, race/ethnicity, prenatal care [PNC] status), obstetrical conditions (abruption, antepartum bleeding, soft tissue conditions [i.e., disorders of the organs and soft tissue of the pelvis]), isoimmune disease, fetal conditions (intrauterine growth restriction [IUGR], excessive fetal growth [macrosomia], oligohydramnios, polyhydramnios), year of delivery, and other pre-existing conditions (presence of renal or hepatic disease, Herpes virus infection) were also included as controls in all models. PNC level was defined as inadequate, adequate, or adequate plus. ${ }^{[41]}$ These characteristics, are known to have a potential effect on SMM and elective repeat CD (outcomes), and were used as potential confounders for the effect of maternal conditions on both of the outcomes. Missing values for maternal highest education level, race/ethnicity and PNC index ranged between $1.6 \%$ and $5.1 \%$. Considering this low rate of missing values, 
observations with missing values were retained in analyses by defining 'unknown' as a separate variable level. Other control variables tested but not included in the model due to non-significant differences in their association with the elective repeat $\mathrm{CD}$ status and/or SMM were: vasa previa, infection, fetal central nervous system abnormality, human immunodeficiency virus (HIV) and isoimmunization-related idiopathic hydrops or hemolytic disease.

Table 1. Administrative codes used to identify the presence of labor (in addition to vaginal delivery)

\begin{tabular}{|c|c|}
\hline ICD-9-CM ${ }^{\mathrm{a}}$ Diagnostic Code & ICD-9-CM Code Description \\
\hline 659.7 & Abnormality in fetal heart rate or rhythm \\
\hline 661 & Abnormality of forces of labor \\
\hline 652.1 & Breech or other malpresentation successfully converted to cephalic presentation \\
\hline 658.2 & Delayed delivery after spontaneous or unspecified rupture of membranes \\
\hline 653 & Disproportion in pregnancy labor and delivery \\
\hline 644.2 & Early onset of delivery \\
\hline 659.0 & Failed mechanical induction of labor \\
\hline 659.1 & Failed medical or unspecified induction of labor \\
\hline 656.3 & Fetal distress affecting management of mother \\
\hline 659.3 & Generalized infection during labor \\
\hline 658.4 & Infection of amniotic cavity \\
\hline 662 & Long labor \\
\hline 659.2 & Maternal pyrexia during labor unspecified \\
\hline 660 & Obstructed labor \\
\hline 658.1 & Premature rupture of membranes \\
\hline 663.0 & Prolapse of cord complicating labor and delivery \\
\hline 649.81 & $\begin{array}{l}\text { Onset (spontaneous) of labor after } 37 \text { completed weeks of gestation but before } 39 \text { completed } \\
\text { weeks gestation, with delivery by (planned) cesarean section }\end{array}$ \\
\hline 649.82 & $\begin{array}{l}\text { Onset (spontaneous) of labor after } 37 \text { completed weeks of gestation but before } 39 \text { completed } \\
\text { weeks gestation, with delivery by (planned) cesarean section, delivered, with mention of } \\
\text { postpartum complication }\end{array}$ \\
\hline \multicolumn{2}{|l|}{ ICD-9-CM Procedure Code } \\
\hline 73.01 & Induction of labor by artificial rupture of membranes \\
\hline 73.4 & Medical induction of labor \\
\hline 96.49 & Other genitourinary instillation \\
\hline 73.1 & Other Surgical Induction Of Labor \\
\hline
\end{tabular}

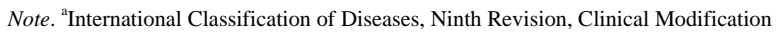

\subsection{Statistical Analysis}

Mediation models were applied to decompose the risk associated with the key maternal health conditions. The two pathways for the potential effect associated with each health condition (exposure) on SMM (outcome) are ${ }^{[1]}$ a direct effect, and ${ }^{[2]}$ an indirect effect by modifying the risk of elective repeat $\mathrm{CD}$ (mediator) that in turn is associated with the risk of SMM (see Figure 1). In our case, all three variables of interest are binary. Of concern is the potential interaction between the effects of the maternal health condition and elective repeat $\mathrm{CD}$ on complications, and interaction are taken into consideration by using the methods developed in Valeri and VanderWeele. ${ }^{[42]}$ To decompose the risk two multiple logistic regression models were fitted:

$$
\ln [p(M) /(1-p(M))]=\beta_{0}+\beta_{1} E+\beta_{2}^{\prime} C
$$

$\ln [p(Y) /(1-p(Y))]=\theta_{0}+\theta_{1} E+\theta_{2} M+\theta_{3} E M+\theta_{4}^{\prime} C$

where we denoted the outcome as $\mathrm{Y}$, the mediator as $\mathrm{M}$, the exposure as $\mathrm{E}$ and vector of covariates as $\mathrm{C}$. The estimated model parameters were used to calculate the natural direct effect (NDE) and natural indirect effect (NIE) as

$$
\begin{aligned}
& N D E=\theta_{1}+\theta_{3}+\left(\beta_{0}+\beta_{2}^{\prime} C\right) \\
& N I E=\theta_{2} \beta_{1}+\theta_{3} \beta_{1}
\end{aligned}
$$

The $N D E$ expresses the change in risk of SMM in the pres- 
ence versus absence of the pre-existing or gestational condition of interest, and for each delivery, the measure of risk of elective repeat $\mathrm{CD}$ is based on other covariates in the absence of the maternal health condition. The NIE expresses the change in risk of SMM in the presence of the maternal health condition and considers the risk of elective repeat $C D$ measured in the presence and in the absence of the maternal health condition. The risk of elective repeat $\mathrm{CD}$ in the absence of the maternal health condition is referred to as the 'natural' elective repeat CD risk and is used here as a counterfactual construct. The total effect (TE) expresses the overall change in risk of SMM for a change in the presence versus the absence of the maternal health condition (irrespective of elective repeat $\mathrm{CD}$ ). The TE is calculated based on the average values for the rest of the model covariates. In the case of our binary outcome models, the TE equals to the product NDE x NIE (even in the presence of interactions and non-linearity).

Table 2. Administrative codes used to define maternal pre-existing and gestational health conditions

\begin{tabular}{|c|c|c|}
\hline Health Condition & ICD-9-CM Diagnostic Code ${ }^{\text {a }}$ & Code definition \\
\hline \multirow[t]{2}{*}{ Diabetes } & $648.8 \mathrm{x}$ & Gestational Diabetes \\
\hline & $250.0 x-250.9 x ; 648.80$ & Chronic diabetes \\
\hline \multirow[t]{3}{*}{ Hypertension } & $642.3 x-642.6 x$ & Gestational hypertension \\
\hline & 401.xx-405.xx; 642.0x-652.2x, 642.7x & Chronic hypertension \\
\hline & $642.9 \mathrm{x}$ & Unspecified hypertension \\
\hline \multirow[t]{14}{*}{ Heart disease } & $648.5 x ; 645 . x x-747 . x x$ & Congenital heart disease \\
\hline & 414.xx, 416.xx, 417.xx, 424.xx, 429.xx & Other heart disease \\
\hline & 410.xx +POA ${ }^{b}, 411 \cdot x x+P O A$ & Acute myocardial infarction (MI) \\
\hline & 413.xx + POA & Angina \\
\hline & 415.xx + POA & Acute pulmonary \\
\hline & $420 . x x+P O A$ & Acute pericarditis \\
\hline & 421.xx + POA & Acute/subacute pericarditis \\
\hline & 422.xx+ POA & Acute myocarditis \\
\hline & 423.xx + POA & Other pericardial \\
\hline & 425.xx + POA & Cardiomyopathy \\
\hline & 426.xx + POA & Conduction disorders \\
\hline & 427.xx + POA & Dysrhythmias \\
\hline & $428 . x x+P O A$ & Heart failure \\
\hline & 35.xx-37.xx; 39.xx & $\begin{array}{l}\text { Operations on heart and pericardium } \\
\text { (procedure codes) }\end{array}$ \\
\hline \multirow[t]{8}{*}{ Mental health disorders } & $296.0 x, 296.2 x-296.8 x$ & Mood disorders \\
\hline & 298.0x, 300.4x, 311.xx & \\
\hline & $300.0 x, 300.2 x, 300.3 x, 308.0 x, 309.81$ & Anxiety disorders \\
\hline & 309.xx & Adjustment disorders \\
\hline & 291.xx, 292.xx, 303.xx-305.xx, 648.3x & Substance use disorders \\
\hline & 295.xx, 297.xx & Psychotic disorders \\
\hline & 293.0x, 293.1x & Cognitive disorders \\
\hline & $307.1 x, 307.50-307.54$ & Eating disorders \\
\hline Obesity & $\begin{array}{l}\text { Body mass index (BMI) }>=30 \mathrm{~kg} / \mathrm{m}^{2} \\
\text { (as noted on birth certificate) or } 278 . \mathrm{xx}\end{array}$ & \\
\hline
\end{tabular}

Note. ${ }^{\mathrm{a}}$ International Classification of Diseases, Ninth Revision, Clinical Modification, ${ }^{\mathrm{b}}$ Present on admission

Analyses were performed separately for each of the maternal health conditions. Due to substantial differences in measured and potentially unmeasured characteristics, separate models were constructed for younger versus older women (aged $>35$ years). All variable rates were compared by elective repeat CD status and by SMM status and tested with a two-sided, two-sample t-test for continuous variables and chi-square tests for categorical variable. For continuous variables, means are reported with standard deviations (SD).

For each of the pre-existing and gestational conditions: chronic diabetes mellitus, gestational diabetes mellitus, chronic hypertension, gestational hypertension, obesity, heart disease, and mental health diagnoses, multiple logistic re- 
gression models were fitted to SMM status using the SAS code provided by Valeri and VanderWeele. ${ }^{[42]}$ When estimating the risk associated with each specific pre-existing or gestational condition, all other conditions were entered in the model as controls along with the confounders. For each model, interactions between the pre-existing and gestational conditions and elective repeat $\mathrm{CD}$ were tested and retained if significant. Adequacy of model fit was assessed with the Hosmer and Lemeshow goodness-of-fit test. ${ }^{[4]}$ We reported the odds ratios (ORs) for natural direct, natural indirect, and total effects with $95 \%$ confidence intervals using the delta method. Significance level for p-values was set at less than 0.05. Analyses were conducted using SAS, version 9.3.

\subsection{Model assumptions}

We assessed whether elective repeat $\mathrm{CD}$ functioned as a mediator between pre-existing and gestational conditions and SMM, if any of the following conditions were met after controlling for confounders: 1) variation in maternal conditions significantly accounted for variation in elective repeat $C D$; 2) variation in elective repeat $C D$ significantly accounted for variation in SMM (elective repeat CD may have a 'protective' effect); 3) variation in maternal conditions significantly accounted for variation in SMM; and 4) variation in maternal conditions accounted for less of the variation in SMM when controlling for elective repeat CD. Causal interpretation of the effects requires the assumption that there are no unmeasured confounders in the relationships between (1) the exposure and outcome, (2) the mediator and outcome, (3) the exposure and mediator, and (4) no mediator-outcome confounder that is affected by the exposure. In an attempt to meet these conditions as best as the data allowed, we included socio-demographic characteristics, obstetrical, fetal and intrapartum conditions, year of delivery, and other pre-existing conditions as potential confounders and conducted separate analyses by age group. Of the four 'no unmeasured confounders' assumptions, the one considered the most likely to be violated is assumption ${ }^{[2]}$ regarding the mediator-outcome relationship. ${ }^{[42,43]}$ That is, that there exist common causes of SMM and elective repeat CD for which we have not adjusted. We estimated the potential bias in the NIE estimates due to such a violation. To this aim, unmediated TEs were obtained from logistic models on each of the outcomes, with the same specification as in the original models but excluding the mediator (elective repeat CD), and modified NIEs were calculated from dividing these (unmediated) TEs by the corresponding NDEs from the mediated models. The potential bias can be assessed by comparing the modified NIEs to the original NIEs, since the unmediated TEs obtained from the models of exposure on outcome are not confounded. ${ }^{[44]}$

\section{RESUlts}

The dataset included 1,001,779 California deliveries between 2010-2011 that were linked to the birth certificate. Of these, we excluded 204 deliveries missing maternal age. Of the remainder, 166,403 were to women with a prior $\mathrm{CD} ; 22,423$ deliveries were excluded due to malpresentation or preterm or multiple gestation or IUFD/stillbirth, and another 1,417 deliveries were excluded due to placenta previa. This resulted in 141,535 women that were retained as the study population. There were 102,948 cases with a CD $(72.7 \%)$ that had no codes to indicate the presence of labor. These cases were assigned to the elective repeat $\mathrm{CD}$ category. The remaining 38,587 deliveries $(27.3 \%)$ were assigned to the TOLAC category. Descriptive data regarding the patient characteristics are presented in Table 3. The overall mean maternal age was 30.5 (5.7) years (ranging from 14-62 years), with 104,465 women $(73.8 \%)$ categorized as "younger" and $37,070(26.2 \%)$ categorized as "older." The racial/ethnic distribution for the study population was: $55.3 \%$ of Hispanic origin, $24.2 \%$ White non-Hispanic, $10.8 \%$ Asian, $5.6 \%$ African-American, and the remainder (4.1\%) were of other or unknown race/ethnicity. Medicaid was the principal insurance payer for $51.7 \%$ of women. The most prevalent pre-existing conditions were obesity $(29.5 \%)$, diabetes mellitus (11.7\%, of which $10.2 \%$ was gestational diabetes only), and hypertension $(5.4 \%$, of which $3.0 \%$ was classified as gestational hypertension only). Overall, younger women were slightly more likely to undergo elective repeat CD compared to older women $(73.2 \%$ versus $71.4 \%$, see Table 3$)$. There were only two conditions that were positively associated with elective repeat $\mathrm{CD}$ across all women: chronic diabetes mellitus and obesity. For both younger and older women, a negative association between elective repeat $\mathrm{CD}$ was evident for the following conditions: Herpes, antepartum bleeding, post-term pregnancy ( $>=40$ and $<=42$ gestational weeks), abruption, mental health disorders, oligohydramnios, and IUGR. Women experienced SMM in $2.3 \%$ of deliveries: $2.2 \%$ for younger and $2.6 \%$ for older women. Table 4 presents the distribution of risk factors for women with and without SMM by maternal age group. Elective repeat CD appeared protective as it was more likely to occur in women with no SMM; this was true for both younger $(69.0 \%$ vs $73.3 \%)$ and older women $(64.1 \%$ vs $71.61 \%)(p<.001)$. As expected, both older and younger women with a failed TOLAC were most likely to experience SMM. Black women were 1.83 times more likely than White women to experience $\mathrm{SMM}(\mathrm{OR}=1.85$ young, $\mathrm{OR}=1.91$ old $)$, and women with a college education were less likely to experience SMM. With respect to the maternal health conditions studied, all categories of hypertension, heart disease, and mental health 
disorders were associated with SMM for both younger and older women. Any diabetes was associated with SMM for older women only, and obesity was not associated with SMM for younger or older women using either obesity definition.

\subsection{Modeling results}

Heart disease, hypertension, and mental health disorders had the highest total effects on SMM in both age groups (Table $5)$. For younger and older women, the total effect OR (95\% CI) for heart disease were $10.7(8.5,13.5)$ and $8.8(6.4,12.2)$, respectively. For hypertension, the total effect OR were 1.7 $(1.4,1.9)$ and $2.0(1.6,2.4)$, and for mental health conditions, the total effect OR were $1.9(1.6,2.3)$ and $1.7(1.3$, 2.3). Decomposition of these total effects revealed that most of the impact of these comorbid conditions on SMM was direct, and was not decreased by elective repeat $\mathrm{CD}$. The direct effects of heart disease for younger and older women were $10.7(8.5,13.4)$ and $8.8(6.3,12.2)$, respectively. There were no significant indirect effects of elective repeat $\mathrm{CD}$ in either younger or older women. Furthermore, there was no association between pre-existing heart disease and the use of elective repeat $\mathrm{CD}$. The direct effects of hypertension for younger and older women were $1.7(1.4,1.9)$ and $2.0(1.6$, $2.4)$, respectively. There were no significant indirect effects of elective repeat CD in either younger or older women. Separate examination of chronic/superimposed and gestational hypertension showed similar risk decomposition and that the direct effect from gestational hypertension was highest: the OR was 1.8 in younger and 2.4 in older women compared to the chronic/superimposed HTN OR of 1.5 in both age groups The direct, indirect, and total effects of any diabetes mellitus, chronic diabetes mellitus, and gestational diabetes mellitus on SMM were insignificant in both age groups. Obesity had a total effect of $0.78(0.66,0.91)$ for older women, as a result of a direct effect of $0.78(0.67,0.92)$. These effects (total and direct) were not statistically significant in younger women. However, for older women, there was a significant indirect decreased risk of $0.99(0.98,0.99)$ for SMM, and no indirect effect in younger women. Re-classifying obesity as "extreme" obesity did not change the direction of the results, yielding a total effect of $0.84(0.61,1.14)$ for older women $0.85(0.71,1.02)$ for younger women. Statistical significance was possibly lost because of a smaller number of cases. Mental health diagnoses had a total effect on SMM of 1.90 (1.60, $2.26)$ and $1.71(1.29,2.28)$ in younger and older women, respectively. The indirect effects were close to " 1 " for both age groups and statistically insignificant for both groups of women. Therefore, almost all the increased risk of SMM appeared attributable directly to the mental health diagnoses. With the exception of 3 models, the Hosmer-Lemeshow lack of fit test was not significant in all logistic regression models fitted in Table 5, indicating good fit. The models for chronic diabetes mellitus, chronic HTN and obesity on elective repeat $\mathrm{CD}$ in younger women had lack of fit $\mathrm{p}$-values between 0.04 and 0.05 indicating a potential deviation in the calibration of these models for the risk of elective repeat CD. No significant changes occurred in any of these OR when the modeling analyses were re-analyzed with the more restricted labor definition. For this definition, $1.2 \%$ of patients previously classified as undergoing a TOLAC were re-classified as having an elective repeat CD. Assessment of potential bias in the NIE estimates due to violation of the assumption of no unmeasured confounding of the exposure-outcome relationship showed mostly small estimate biases of less than $3 \%$ absolute change.

\section{Conclusion}

This study attempted to quantify the effect of several key conditions on SMM, namely: hypertension (chronic and gestational), diabetes mellitus (chronic and gestational), heart disease, obesity, and mental health disorders. Of these conditions, only hypertension (both chronic and gestational), heart disease, and mental health disorders had a direct effect on SMM in pregnant women with a prior CD. Neither diabetes (chronic or gestational) nor obesity was associated with SMM. The study also found that the effect of the conditions studied on SMM was not mediated (significantly increased or decreased) by the decision to undergo elective repeat $\mathrm{CD}$.

From 2011-2015, the CDC reported that hypertensive disorders of pregnancy were responsible for $6.8 \%$ of all pregnancyrelated deaths. ${ }^{[1]}$ Delivery hospitalizations with hypertensive disorders are also well-known to be associated with SMM. ${ }^{[12,45-47]}$ Here, "any" hypertension, which includes both chronic and gestational hypertension, was strongly associated with SMM [total effect $1.7(1.4,1.9)$ and $2.0(1.6,2.4)$ for younger and older women, respectively]. Reports suggest that early onset of the disease, and delays in receiving treatment, increase this risk, ${ }^{[19]}$ and that SMM is largely related to acute renal failure, pulmonary edema, adult respiratory distress syndrome, puerperal cerebral vascular disorder, and disseminated intravascular coagulation syndrome. ${ }^{[46]}$ The risk of SMM for affected women did not increase or decrease with elective repeat $\mathrm{CD}$. Of those who had severe hypertensive disorders, younger women, but not older women, were more likely to undergo elective repeat $\mathrm{CD}$.

Cardiovascular diseases were the leading cause of all pregnancy-related mortality from 2011-2015 in the U.S., responsible for $15.1 \%$ of these deaths, and an additional $10.8 \%$ of deaths due to cardiomyopathy. ${ }^{[1]}$ Although dramatic improvements in the medical and surgical management of congenital heart disease have contributed to a progressive 
decline in maternal deaths due to congenital heart disease, ${ }^{[48]}$ the leading causes are now acquired diseases, e.g., acquired heart valve defects, cardiomyopathy, arrhythmia, and coronary heart disease. ${ }^{[21,23]}$ The risk of adverse events during pregnancy for women with pre-existing cardiac disease is determined by their ability to adapt to the associated physiological changes. Physiological adaptation to pregnancy imposes a major stress on the cardiovascular system, with a $50 \%$ increase in blood volume and cardiac output, and a decrease in systemic vascular resistance. ${ }^{[23]}$ Structural changes in the vascular wall, such as hypertrophy of vascular endothelium and smooth muscle, also occur. ${ }^{[14]}$ Pre-existing heart disease was highly related to SMM [total effect OR 10.7 $(8.5,13.5)$ and $8.8(6.4,12.2)$, for younger and older women, respectively]. This risk did not increase or decrease with elective repeat $\mathrm{CD}$. Women with heart disease were not more likely to undergo elective repeat $\mathrm{CD}$.

Women with mental health disorders were also more at risk for SMM [total effect $1.9(1.6-2.3)$ and $1.7(1.3,2.3)$, for younger and older women, respectively]. Other investigators have identified this connection, ${ }^{[6,10,16]}$ although the basis of this relationship deserves more detailed exploration. For example, opioid use and abuse, which are included in the definition of these disorders, has been directly linked to SMM,${ }^{[10]}$ specifically, pregnancy-related mortality, cardiac arrest, placental abruption, and blood transfusion. ${ }^{[49]}$ Alternatively, depression has been linked to chronic diseases that in turn may be linked to SMM. ${ }^{[50]}$ However, a comprehensive understanding is lacking regarding which types of SMM are predominant in this population and its sub-populations, and why. Women with mental health disorders were less likely to undergo elective repeat $\mathrm{CD}$.

Obesity has been reported as a potential risk factor for SMM in a variety of investigations. ${ }^{[4,7,51,52]}$ However, we found no positive effect of obesity on SMM [total effect OR 0.92 (0.84$1.01)$ and 0.78 (0.66-0.91), for younger and older women respectively]. This is likely to be the result of our adjustment for confounders, as obesity may be highly related to other chronic conditions. ${ }^{[26]}$ No substantial changes in the models were found when defining obesity as "extreme," i.e., BMI > $40 \mathrm{~m} / \mathrm{kg} 2$. Obese women were more likely to undergo elective repeat CD in our study, which is consistent with studies quoting a lesser degree of successful labor; ${ }^{[35]}$ however, elective repeat $\mathrm{CD}$ did not appear to increase or decrease their risk of SMM.

Women with either chronic or gestational diabetes mellitus did not appear to be at risk for SMM because of their condition. This is in contrast to reports from other investigators who found an association between diabetes and SMM. ${ }^{[4,26]}$
This discrepancy in findings may be attributed to different approaches to this question, such as inclusion of different study populations, more restrictive definitions of SMM, or minimal adjustment for confounders.

In a previous study using a study population of nulliparous women who labored with term, singleton, vertex (NTSV) gestations and who delivered in California between 2008$2010,{ }^{[37]}$ we found that the modeled ORs for the direct effect of emergent CD on SMM were 2.0-2.7 for hypertension, 6.67.7 for heart disease, and 1.4-1.6 for mental health diagnoses. In this previous work, we did not identify a direct effect for diabetes mellitus or obesity. In the presence of hypertension, heart disease, or mental health disorders, the increased risk of SMM mediated by an emergent CD was low, resulting in a $0-11 \%$ increase over the direct effect from the condition itself. Although the NTSV population is distinct from the study population used here, both studies identified that hypertension, heart disease, and mental health disorders were the conditions associated with SMM, and that obesity and diabetes mellitus were not. The interpretation of the indirect effects of the conditions mediated by $\mathrm{CD}$ is difficult to compare because the current study considered elective repeat CD, and the other considered emergent $\mathrm{CD}$ are two very different clinical scenarios.

The current study provides evidence that, among women with prior $\mathrm{CD}$, it is the health condition of the patient that determines her risk of SMM and not whether she underwent an elective repeat $\mathrm{CD}$. It further confirmed that the greatest risk of SMM was primarily in Black women, ${ }^{[7,53-55]}$ whose increased risk has been primarily attributed to a higher incidence of hypertensive disorders in pregnancy. ${ }^{[45]}$ Recently, Lindquist et al, in an Australian study, identified "social disadvantage" as an independent risk factor for SMM, ${ }^{[33]}$ and this remains to be formally explored in the United States. Although coverage with Medicaid insurance was not highly associated with SMM, our study did identify that both younger and older college-educated women were less likely to experience SMM, which is consistent with the Lindquist et al results. The current study strengths are usage of a large population-based sample and a linked dataset allowing the evaluation and inclusion of numerous covariates that were potentially related to maternal outcomes. The specific focus on women with a prior $\mathrm{CD}$ as the study population and the age stratification facilitated the interpretation of the study results.

Limitations of the current study include the shortcomings of retrospective administrative data. We could not distinguish the severity of the SMM identified, nor whether patients who labored or had a scheduled CD differed in this severity. For 
example, to meet the SMM diagnosis, ${ }^{[40]}$ a patient may have received one unit of packed red blood cells, or she may have received four, and this would not be distinguished by our analysis. Another limitation is that we did not distinguish between induction of labor versus spontaneous labor. Induction of labor carries its own risks and for some of these maternal conditions, e.g., severe pre-eclampsia, awaiting spontaneous labor may not be considered feasible or safe. ${ }^{[17]}$

Furthermore, our identification of who did and did not labor is also limited by the clinical scenario. Given our data sources, it is impossible to know the length of time a woman labored, and we classified all women with any indication of labor as having labored. For example, women who intended to have an elective repeat $\mathrm{CD}$ who went into labor prior to the scheduled surgery were classified as having labored. This likely resulted in classifying more women in this category than had intended to labor, and decreasing the successful labor rate. Because failed labor is more highly associated with SMM than elective $\mathrm{CD}$, our classification may have decreased the positive effect of a labor attempt on SMM essentially biasing it toward the null. Our re-analysis of the models using the more restricted labor definition did not suggest that our results were highly sensitive to this classification. There is currently no definition of a minimum number of hours in labor that would be acceptable for classification of an elective repeat $\mathrm{CD}$, and there is also no source for those data. The California birth certificate attempts to collect in- formation regarding whether a woman labored, but a large proportion of missing data renders this variable unusable. The substantially increased SMM that we found associated with patients classified as having a failed vs. successful labor is consistent with longstanding reports in the literature, ${ }^{[35]}$ and suggests that any defined threshold for length of labor would likely retain some degree of misclassification. The application of these findings to clinical decisions must always account for individual patient and fetal characteristics, and the hospital environment, i.e., the resources and the timeliness of availability of these resources. A further caution is that these analyses apply only to short-term outcomes, namely SMM, and not to longer-term effects that may occur or be assessed after the delivery hospitalization. Finally, our analysis is limited to women with a history of $\mathrm{CD}$, but does not account for those with a history of prior vaginal birth or number of prior $\mathrm{CD}$, both of which could impact subsequent vaginal delivery and SMM.

In summary, heart disease, hypertension, and mental health disorders all had a direct effect on SMM. We found no indirect effect of the pre-existing and gestational conditions tested mediated by elective repeat CD on SMM. Further exploration of the risks of mental health disorders should be pursued.

\section{CONFLicts OF INTEREST Disclosure}

The authors declare no conflict of interest.

\section{REFERENCES}

[1] Centers for Disease Control and Prevention. Pregnancy Mortality Surveillance System. Trends in pregnancy-related deaths. Available at: http://www.cdc.gov/reproductivehealth/materna linfanthealth/pmss.html(Accessed July 12, 2019).

[2] Fingar KF, Hambrick MM, Heslin KC, et al. Trends and disparities in delivery hospitalizations involving severe maternal morbidity, 2006-2015. HCUP Statistical Brief \#243. September 2018. Agency for Healthcare Research and Quality, Rockville, MD. Available at: www.hcup-us.ahrq.gov/reports/statbriefs/sb243-Sev ere-Maternal-Morbidity-Delivery-Trends-Disparities .pdf (Accessed July 12, 2019).

[3] Centers for Disease Control and Prevention. Severe maternal morbidity in the United States. Trends in severe maternal morbidity in the United States 1993-2014. Available at: https://www.cdc.gov/reproductivehealth/maternali nfanthealth/severematernalmorbidity.html

[4] Grobman WA, Bailit JL, Rice MM, et al. For the Eunice Kennedy Shriver National Institute of Child Health and Human Development (NICHD) Maternal-Fetal Medicine Units (MFMU) Network. Frequency of and factors associated with severe maternal morbidity. Obstet Gynecology. 2014; 123: 804-810. PMid:24785608. https://doi.org/10.1097/A0G.0000000000000173
[5] Wen SW, Huang L, Liston R, et al. For the Maternal Health Study Group, Canadian Perinatal Surveillance System. Severe maternal morbidity in Canada, 1991-2001. CMAJ. 2005; 173(7):759-764. PMid:16186582. https://doi.org/10.1503/cmaj. 045156

[6] Lutomski JE, Greene RA, Byrne BM. Severe maternal morbidity during childbirth hospitalisation: a comparative analysis between the Republic of Ireland and Australia. Eur J Obstet Gynecol Reprod Biol. 2012; 163: 148-153. PMid:22640728. https: //doi.org/10.1016/j.ejogrb. 2012.05.003

[7] Gray KE, Wallace ER, Nelson KR, Reed SD, Schiff MA. Populationbased study of risk factors for severe maternal morbidity. Paediatr Perinatal Epidemiol. 2012; 26: 506-514. PMid:23061686. https://doi.org/10.1111/ppe.12011

[8] Berg CJ, MacKay AP, Cheng Q, et al. Overview of maternal morbidity during hospitalization for labor and delivery in the United States: 1993-1997 and 2001-2005. Obstet Gynecol. 2009; 113(5): 1075-1081. PMid:19384123. https://doi.org/10.1097/AOG.0b013e3181 a09fc0

[9] Fridman M, Korst LM, Chow J, et al. Trends in maternal morbidity before and during pregnancy in California. Am J Public Health 2014; 104 (Suppl): 1:S49-S57. PMid:24354836. https: //doi.org/10.2105/AJPH. 2013.301583

[10] Arendt KW. The 2016 Hughes Lecture: what's new in maternal morbidity and mortality. In J Obstet Anesth. 2016; 26: 59-70. 
PMid:26847944. https ://doi.org/10.1016/j.ijoa.2015.12 .003

[11] Campanharo FF, Cecatti JG, Haddad SM, et al. Brazilian Network for Surveillance of Severe Maternal Morbidity Study Group. The impact of cardiac diseases during pregnancy on severe maternal morbidity and mortality in Brazil. PLoS ONE. 2015; 10(12): e0144385. PMid:26650684. https://doi.org/10.1371/journal.pone.0 144385

[12] Kilpatrick SJ, Abreo A, Greene N, et al. Severe maternal morbidity in a large cohort of women with acute severe intrapartum hypertension. Am J Obstet Gynecol. 2016; 215(1): 91.e1-7. PMid:26829504. https://doi.org/10.1016/j.ajog.2016.01.176

[13] Johnson JL, Farr SL, Dietz PM, et al. Trends in gestational weight gain: the Pregnancy Risk Assessment Monitoring System, 20002009. Am J Obstet Gynecol. 2015; 212: 806.e1-8. PMid:25637844. https://doi.org/10.1016/j.ajog.2015.01.030

[14] Huisman CM, Zwart JJ, Roos-Hesselink JW, et al. Incidence and predictors of maternal cardiovascular mortality and severe morbidity in the Netherlands: a prospective cohort study. PLOS ONE. 2013; 8(2): e56494. PMid:23457576. https://doi.org/10.1371/jo urnal. pone. 0056494

[15] Zwart JJ, Richters JM, de Vries JIP, et al. Severe maternal morbidity during pregnancy, delivery and puerperium in the Netherlands: a nationwide population-based study of 371,000 pregnancies. BJOG. 2008; 115: 842-850. PMid:18485162. https ://doi .org/10.111 1/j.1471-0528.2008.01713.x

[16] Creanga AA, Berg CJ, Ko JY, et al. Maternal mortality and morbidity in the United States: where are we now? J Womens Health. 2014; 23(1): 3-9. PMid:24383493. https ://doi.org/10.1089/ jwh. 2013.4617

[17] Geller SE, Cox SM, Kilpatrick SJ. A descriptive model of preventability in maternal morbidity and mortality. J Perinatol. 2006; 26: 79-84. PMid:16407964. https://doi.org/10.1038/sj.jp.7211432

[18] American College of Obstetricians and Gynecologists (ACOG). Levels of maternal care. Obstetric Care Consensus No. 2. Obstet Gynecol. 2015; 125(2): 502-515. PMid:25611640. https://doi.org/10.1 097/01.AOG.0000460770.99574.9f

[19] Zanette E, Parpinelli MA, Surita FG, et al. Brazilian Network for Surveillance of Severe Maternal Morbidity Group. Maternal near miss and death among women with severe hypertensive disorders: a Brazilian multicenter surveillance study. Reprod Health. 2014; 11: 4. PMid:24428879. https ://doi.org/10.1186/1742-4755-1 1-4

[20] Bateman BT, Tsen LC. Anesthesiologist as epidemiologist: insights form registry studies of obstetric anesthesia-related complications. Anesthesiol. 2014;120:1311-1312. PMid:24845916. https : //doi.org/10.1097/ALN.0000000000000252

[21] Regitz-Zagrosek V, Geibel-Zehender A, Gohlke-Barwolf C, et al. Cardiovascular diseases in pregnancy. Dtsch Arztebl Int. 2011; 108(16): 267-73. PMid:21603561. https : //doi .org/10.3238/arztebl. 2011.0267

[22] Zollner J, Curry R, Johnson M. The contribution of heart disease to maternal mortality. Curr Opin Obstet Gynecol. 2013; 25: 91-97. PMid:23411474. https://doi.org/10.1097/GC0.0b013e3283 $5 e 0 f 11$

[23] Curry R, Swan L, Steer PJ. Cardiac disease in pregnancy. Curr Opin Obstet Gynecol. 2009; 21: 508-513. PMid:19779340. https : //doi.org/10.1097/GC0.0b013e328332a762

[24] Amorim MMR, Katz L, Barros AS, et al. Maternal outcomes according to mode of delivery in women with severe preeclampsia: a cohort study. J Matern Fetal Neonatal Med. 2015; 28(6): 654-660.
PMid:24866351. https://doi.org/10.3109/14767058.2014. 928689

[25] American College of Obstetricians and Gynecologists (ACOG). Task Force on Hypertension in Pregnancy. Hypertension in Pregnancy. Washington, DC: ACOG 2013.

[26] Pallasmaa N, Ekblad U, Gissler M. The impact of maternal obesity, age, pre-eclampsia and insulin dependent diabetes on severe maternal morbidity by mode of delivery - a register-based cohort study. Arch Gynecol Obstet 2015;291:311-318. PMid:25115277. https://doi.org/10.1007/s00404-014-3352-z

[27] Cunningham FG, Bangdiwala S, Brown SS, et al. National Institutes of Health Consensus Development Conference Statement: Vaginal Birth After Cesarean: New Insights. March 8-10, 2010. Obstet Gynecol 2010;115(6):1279-1295.

[28] Gregory KD, Jackson S, Korst L, et al. Cesarean versus vaginal delivery: whose risks? Whose benefits? Am J Perinatol. 2012; 29(1): 7-18. PMid:21833896. https://doi.org/10.1055/s-0 031-1285829

[29] Liu S, Liston RM, Joseph KS, et al. For the Maternal Health Study Group of the Canadian Perinatal Surveillance System. Maternal mortality and severe morbidity associated with low-risk planned cesarean delivery versus planned vaginal delivery at term. CMAJ. 2007; 176(4): 455-460. PMid:17296957. https://doi.org/10.1 503 /cmaj . 060870

[30] Pallasmaa N, Ekblad U, Gissler M. Severe maternal morbidity and the mode of delivery. Acta Obstet Gynecol Scan. 2008; 86: 662-668. PMid:18568466. https://doi.org/10.1080/00016340802108 763

[31] Patel RM, Jain L. Delivery after previous cesarean: short-term perinatal outcomes. Semin Perinatol. 2010; 34: 272-280. PMid:20654778. https://doi.org/10.1053/j.semperi.2010.03.007

[32] Srinivas SK, Stamilio DM, Stevens EJ, et al. Predicting failure of a vaginal birth attempt after Cesarean delivery. Obstet Gynecol. 2007; 109: 800-805. PMid:17400839. https://doi.org/10.1097/01 .AOG.0000259313.46842.71

[33] Lindquist AC, Kurinczuk JJ, Wallace EM, et al. Risk factors for maternal morbidity in Victoria, Australia: a population-based study. BMJ Open 2015;5e007903. PMid:26307615. https : //doi .org/ 10.1136/bmjopen-2015-007903

[34] Wen SW, Rusen ID, Walker M, et al. For the Maternal Health Study Group, Canadian Perinatal Surveillance System. Am J Obstet Gynecol. 2004; 191: 1263-1269. PMid:15507951. https : //doi.org/10.1016/j.ajog.2004.03.022

[35] American College of Obstetricians and Gynecologists (ACOG). Vaginal Birth after previous cesarean delivery. ACOG Practice Bulletin No. 115. Washington DC: ACOG, 2010.

[36] Schisterman EF, Cole SR, Platt RW. Overadjustment bias and unnecessary adjustment in epidemiologic studies. Epidemiol. 2009; 20(4): 488-495. PMid:19525685. https ://doi.org/10.1097/EDE. Ob 013e3181a819a1

[37] Fridman M, Greene NH, Lawton E, et al. Evaluating the effect of maternal health conditions on severe maternal morbidity adjusting for cesarean delivery: a mediation analysis approach. J Epidemiol Res. 2016; 2(2): Jan 20. https ://doi .org/10.5430/jer.v2n2p36

[38] Gilbert WM, Nesbitt TS, Danielsen B. The cost of prematurity: quantification by gestational age and birthweight. Obstet Gynecol. 2003;102:488-492. PMid:12962929. https://doi.org/10.109 7/00006250-200309000-00011

[39] Korst L, Fridman M, Lu M, et al. Monitoring childbirth morbidity using hospital discharge data: further development and application of a composite measure. Am J Obstet Gynecol. 2014; 211(3): 268.e1-e16. 
PMid:24631432. https://doi.org/10.1016/j.ajog. 2014.03 .011

[40] Callaghan WM, Creanga AA, Kuklina EV. Severe maternal morbidity among delivery and postpartum hospitalizations in the United States. Obstet Gynecol. 2012; 120: 1029-1036. PMid:23090519. https://doi.org/10.1097/AOG.0b013e31826d60c5

[41] Kotelchuck M. An evaluation of the Kessner Adequacy of Prenatal Care Index and a proposed adequacy of prenatal care utilization index. Am J Public Health. 1994; 84: 1414-1420. PMid:8092364. https://doi.org/10.2105/AJPH . 84.9.1414

[42] Valeri L, VanderWeele TJ. Mediation analysis allowing for exposuremediator interactions and causal interpretation: theoretical assumptions and implementation with SAS and SPSS macros. Psychol Methods. 2013; 18(2): 137-150. PMid:23379553. https://doi.org/ $10.1037 / \mathrm{a} 0031034$

[43] Hosmer D.W. and Lemeshow S. A goodness-of-fit test for the multiple logistic regression model. Communications in Statistics 1980; A10: 1043-1069. https://doi.org/10.1080/03610928008827 941

[44] Friedman AM, Ananth CV, Huang Y, et al. Hospital delivery volume, severe obstetrical morbidity, and failure to rescue. Am J Obstet Gynecol. 2016; 215(6): 795.e1-795.e14. PMid:27457112. https://doi.org/10.1016/j.ajog.2016.07.039

[45] Zhang J, Meikle S, Trumble A. Severe maternal morbidity associated with hypertensive disorders in pregnancy in the United States. Hypertens Pregnancy. 2003;22(2):203-12. PMid:12909005. https://doi.org/10.1081/PRG-120021066

[46] Kuklina EV, Ayala C, Callaghan WM. Hypertensive disorders and severe obstetric morbidity in the United States. Obstet Gynecol. 2009; 113: 1299-1306. PMid:19461426. https://doi.org/10.1097/ AOG.0b013e3181a45b25

[47] Gilbert WM, Young AL, Danielsen B. Pregnancy outcomes in women with chronic hypertension: a population-based study. J Reprod Med. 2007; 52: 1046-51.
[48] Thompson JL, Kuklina EV, Bateman BT, et al. Medical and obstetric outcomes among pregnant women with congenital heart disease. Obstet Gynecol. 2015; 126: 346-354. PMid:26241425. https://doi.org/10.1097/AOG.0000000000000973

[49] Maeda A, Bateman BT, Clancy CR, et al. Opioid abuse and dependence during pregnancy: temporal trends and obstetrical outcomes. Anesthesiol. 2014; 121: 1158-1165. PMid:25405293. https : //doi.org/10.1097/ALN.0000000000000472

[50] Farr SL, Hayes DK, Bitsko RH, et al. Depression, diabetes, and chronic disease risk factors among U.S. women of reproductive age. Prev Chronic Dis. 2011; 8.

[51] Schummers L, Hutcheon JA, Bodnar LM, et al. Risk of adverse pregnancy outcomes by prepregnancy body mass index: a populationbased study to inform prepregnancy weight loss counseling. Obstet Gynecol. 2015; 125: 133-143. PMid:25560115. https://doi.or g/10.1097/AOG.0000000000000591

[52] Mourad M, Silverstein M, Bender S, et al. The effect of maternal obesity on outcomes in patients undergoing tertiary or higher cesarean delivery. J Mat Fetal Neonatal Med. 2015; 28(9): 898-993. PMid:25058127. https://doi.org/10.3109/14767058.2014. 941284

[53] Howell EA, Egorova N, Balbierz A, et al. Black-white differences in severe maternal morbidity and site of care. Am J Obstet Gynecol. 2016; 214: 122.e1-7. PMid:26283457. https://doi.org/10.101 6/j.ajog. 2015.08.019

[54] Creanga AA, Bateman BT, Kuklina EV, et al. Racial and ethnic disparities in severe maternal morbidity: a multistate analysis, 20082010. Am J Obstet Gynecol. 2014; 210: 435.e1-8. PMid:24295922. https://doi.org/10.1016/j.ajog.2013.11.039

[55] Nair M, Kurinczuk JJ, Knight M. Ethnic variations in severe maternal morbidity in the UK- a case control study. PLoS One. 2014; 9(4): e95086. PMid:24743879. https://doi.org/10.1371/journal. pone. 0095086 